\title{
NATUREZA EM ALEXANDER VON HUMBOLDT: entre a ontologia e o empirismo
}

\author{
Prof. Dr. Antonio Carlos Vitte \\ Pesquisador $\mathrm{CNPq}$ \\ Departamento de Geografia, Instituto de Geociências, Universidade Estadual de Campinas \\ Rua João Pandiá Calógeras, 51 - CEP: 13087-970, Cx.Postal: 6152 - Campinas (SP), Brasil \\ Tel./Fax (+55 19) 35214570 e 35214552 - vitte@uol.com.br
}

Msc. Roberison Wittgeinstein Dias da Silveira r_silveira@yahoo.com.br

\begin{abstract}
RESUMO
O artigo discute o papel do materialismo e da naturphilosophie na construção do conceito de natureza em Alexander von Humboldt. A partir do retrabalhamento das concepções materialistas e empiristas e inserindo a natureza em uma concepção ontológica, Humboldt avança e permite o aprofundamento analítico sobre a superfície da Terra e de seus processos, pois cria uma nova ciência e está cria a imagem moderna de uma natureza, para além do mecanicismo. A geografia, é esse produto e sua reflexão necessita de uma forte fundamentação metafísica a mesma que permitiu a Humboldt recriar as noções de Terra e Mundo.
\end{abstract}

Palavras-chave: Humboldt, natureza, materialismo, metafísica, Geografia Física.

\begin{abstract}
The article discusses the role of materialism and Naturphilosophie in building the concept of nature in Alexander von Humboldt. From the materialist reworking of conceptions, empiricists and inserting nature in an ontological conception, Humboldt advances and allows for a deeper analytical about the Earth's surface and their processes, it creates a new science and is creating the modern image of a nature beyond the mechanism. The geography is the product and its reflection needs a strong metaphysical foundation, which allowed it to recreate the concept of Humboldt Earth and World.
\end{abstract}

Key words: Humboldt, nature, materialism, metaphysics, Physical Geography.

\section{RESUMEN}

El artículo analiza el papel del materialismo y la Naturphilosophie en la construcción del concepto de naturaleza en Alexander von Humboldt. De la reelaboración de las concepciones empirista y materialista de la naturaleza y entrar en un concepción ontológica, los avances de Humboldt y permite un análisis más profundo en la superficie de la tierra y sus procesos, crea una nueva ciencia y la creación de la imagen moderna de una naturaleza más allá del mecanismo. Geografía, es este producto y reflexión requiere una sólida base metafísica que permitió a la misma Humboldt recrear los conceptos de la Tierra y el Mundo.

Palabras clave: Humboldt, la naturaleza, el materialismo, la metafísica, la física Geografía.

\section{INTRODUÇÃO}

Os trabalhos e a vida intelectual de Alexander Von Humboldt se inserem em um momento de rupturas e transformações no âmbito do conhecimento. De uma maneira geral, observamos no final do século XVIII e início do XIX um processo de sistematização científica, um arranjo disciplinar que colocará a ciência em sua configuração moderna. A construção destes recortes e limites científicos modernos se contrapõe a uma tendência enciclopedista e, do mesmo modo, à ligação aos conteúdos e objetivos filosóficos e científicos. Na mesma medida, toma forma uma reação contra esta tendência do saber e sua forma de articulação e produção do conhecimento.

O Sturm und Drang e, posteriormente, o Romantismo alemão (e de alguma maneira também a vertente classicista) se colocarão como contraponto na construção de um conhecimento estritamente formal, alheio ao papel da sensibilidade, da intuição, da estética e da arte, ainda que seja necessário admitir que há uma relação de mútua influência entre a ciência produzida na época e as idéias filosóficas do romantismo alemão, como por exemplo a perspectiva de unidade (organismo) 
e a concepção da síntese (atração) entre contrários (magnetismo). Por trás desse conjunto de transformações e embates se apresenta àquele tempo a tensão que acompanha o saber filosófico desde sua origem: a tensão entre as cosmovisões idealista e materialista.

A concepção geral da realidade (cosmologia), o papel atribuído à materialidade, as atribuições e possibilidades do sujeito e a fundamentação última do saber e da realidade dizem respeito às discussões postas desde a origem do saber filosófico e, a esse tempo, emergem nesse conjunto de transformações operadas no contexto de Humboldt. Introduzido e ativamente produzindo conhecimento nesse cenário intelectual, Alexander von Humboldt revela em suas obras esse conjunto de transformações e, mais do que isso, se coloca conscientemente, a partir da criação de uma forma de ciência inovadora, o desafio de responder ao embate ontológico que acompanha estas discussões.

Quando examinamos os trabalhos de Alexander Von Humboldt encontramos, a primeira vista, uma tendência descritiva, uma forma de expressão discursiva onde procurou destacar as especificidades locais e as particularidades que competem a uma materialidade dada, quer dizer, um esforço que poderia ser associado a um saber enciclopedista e materialista. Nesse sentido, não haveria grande dificuldade, na medida em que esta proposta é relativamente usual em seu contexto e, de nenhuma forma, inova no campo do conhecimento científico. Não obstante, outro elemento que é incorporado na análise é a perspectiva de uma ordenação, uma relação, e mesmo uma lei, como admite em muitas de suas passagens, para esse conjunto de particulares descritos; ou seja, Humboldt evoca em seu saber uma construção que assume forma científica, procurando elementos regulares no conjunto de casos específicos. Também nesse sentido não se encontrariam maiores dificuldades, já que estes são os pressupostos comuns de um método indutivo aplicado aos estudos regionais e fisionômicos.

Além dos pressupostos de um método estritamente indutivo e correlato aos pressupostos mecanicistas, se apresenta nos trabalhos de Humboldt, um conjunto de reflexões que pretendem uma ordenação causal não linear e a consideração de uma finalidade independente para o domínio da natureza. O reconhecimento de um telos natural independente da determinação da razão se associa ao processo de ruptura com as diretrizes mecanicistas que legitimavam a forma de saber científica posta naquele contexto e, mais do que isso, se associavam diretamente com o Sturm und Drang e, logo depois, com o Romantismo alemão. Não só os argumentos científicos que ganham força com a concepção de organismo como também as reflexões poéticas e filosóficas da Alemanha de início do XIX permearam toda a produção e construção científica de Humboldt. Aqui, nesse confluir de métodos e pressupostos diametralmente opostos, se apresenta o truncado campo sob o qual temos que nos debruçar na análise do saber proposto por Humboldt; aqui reside todo o valor de sua obra e toda a dificuldade de concebê-la e sistematizá-la em um saber científico.

Sua organização do conceito de paisagem, por exemplo, é o produto do embate entre as cosmovisões materialista e idealista. Esse conceito é o produto de uma confluência de pressupostos e métodos, produto de um embate ontológico que desde o século XVIII acompanhou as reflexões sobre a natureza e sua espacialidade na superfície da Terra.

\section{ENCICLOPEDISMO, MATERIALISMO E ORDENAÇÃO EM HUMBOLDT}

Nessa primeira parte vamos explorar alguns pontos da ciência humboldtiana que se associam, de modo geral, com o enciclopedismo, o materialismo e os princípios ordenadores do racionalismo. Lembramos que, em verdade, trata-se aqui de um esforço para tornar evidente o conjunto de teorias e diretrizes metodológicas incorporadas nos trabalhos de Humboldt, e não da defesa de uma suposta orientação mecanicista ou estritamente enciclopedista-materialista de suas obras. Muito pelo contrário, a exposição destas diretrizes dialogam a todo tempo com uma perspectiva geral mais ampla, como teremos oportunidade de demonstrar no fechamento deste capítulo. Enfim, o que nos interessa nessa primeira parte é justamente destacar o papel desempenhado por essas formulações na organização metodológica de sua ciência. 
O esforço descritivo e o acúmulo de particulares no conjunto de suas obras nos remetem, a princípio, ao interesse enciclopedista de reunir o maior número possível de elementos de uma realidade materialmente dada e defini-los com precisão. Essa concepção enciclopedista pode ser explicada de muitas maneiras; a principal delas diz respeito à própria formação de Humboldt.

Em 1789, depois de ter passado pela Universidade de Frankfurt, nosso investigado vai para Göttingen. Lá, os anos de aprendizado marcam um momento crucial na sua formação e na ampliação de seus horizontes e possibilidades. Recebe a orientação de eminentes professores como Christian Gottlob Heyne (1729-1812), Karl Frederic Eichhorn (1781-1854) e Lichtemberg (1742-1799), além de Blumenbach (1752-1840), que lhes ensinam fisiologia, ciências da natureza e anatomia comparada. Gayet (1995) defende que é nesse período que se estrutura em Humboldt uma perspectiva enciclopedista e materialista. Embora haja nesses autores uma tendência enciclopedista, devemos destacar que, no caso específico de Blumenbach, o materialismo se introduz numa perspectiva mais ampla, como uma reação à concepção estritamente mecanicista, evitando uma redução "pura e simplesmente às forças físico-mecânicas" “ (LENIOR In CUNNINGHAM \& JARDINE, 1990, p. 120, trad. Nossa). De todo modo, essa concepção não poderia ter exercido influencia em Humboldt nesse período, haja vista que a mesma refere-se a uma em data posterior a sua passagem por Göttingen. Lenior (In: CUNNINGHAM \& JARDINE, 1990) destacou que nesse momento em Göttingen, , os trabalhos de Blumenbach procuravam estabelecer uma aproximação com os esforços desenvolvidos por Kant em sua Crítica do Juízo (Kant, 1995). Assim, Blumembach, influenciado por Kant, procurava, produzir uma integração entre as concepções mecânicas e teleológicas; no caso de Blumenbach com a formulação de um "vitalismo materialista". Essa integração entre uma concepção mecânica e uma teleológica refletia uma recuperação da filosofia leibniziana em Kant que passou a ocorrer a partir das décadas de 1780 e 1790, quando o mesmo Kant elaborou seus estudos sobre as raças e formulou a sua Crítica da Faculdade de Julgar, ou seja, exatamente depois da passagem de Humboldt por Göttingen.

Capel (1981), por sua vez, dirá que essa dimensão enciclopedista está intimamente relacionada com a utilização de um método comparativo. O sentido de recolher inúmeras informações e defini-las com precisão residiria no projeto maior de comparar e ordenar. A utilização desse método, na visão de Capel, está ligada à formação botânica, geológica e zoológica de Humboldt e, sobretudo, à anatomia comparada. A outra parte estruturadora do seu método teria sido adquirida, ainda segundo Capel (1981), por influência de Georg Forster. Com ele, Humboldt realizou sua primeira viagem como pesquisador para fora das fronteiras alemãs, inicialmente ainda na Alemanha, para o Baixo Reno, depois para Holanda, Inglaterra e França. Em seu retorno, se estabeleceu em Hamburgo, na Academia de Comercio de Büsc, onde se instrui em estatística econômica e legislação cameralística (Minguet In: Humboldt, s.d.). Aqui, com a contribuição de Willdenow, trabalhou nas suas primeiras publicações científicas, voltadas a princípio para a botânica e para os estudos geológicos. A publicação de sua Mineralogische Beobachtungen über einige Basalte am Rhein é claramente influenciada por G. Forster e nela já se apresenta o método comparativo do qual nos fala Capel (1981).

Ainda com relação à viagem, é importante destacar que ela acontece no período que segue a Revolução Francesa, despertando em Humboldt um entusiasmo profundo pelo pensamento francês. Os fundamentos do enciclopedismo que ele havia assimilado em seus primeiros anos acadêmicos podem ter sido reforçados por esse contato; contato esse que será mantido por toda a sua vida intelectual.

Importa nesse momento compreender que se estrutura no pensamento de Humboldt uma necessidade de ampliar o conhecimento particular; reunir descrições com o intuito de colocar o conjunto de informações específicas a serviço de um pensamento ordenador. Ainda segundo uma visão superficial de sua proposta de ciência, o escopo de Humboldt seria pensar os diferentes elementos que compõem a esfera do mundo natural e atribuir a estes, a partir de um método comparativo já 
disposto em seu contexto, uma possível ordenação ou agrupamento, reconhecendo semelhanças e diferenças no campo objetivo da natureza e sistematizando-as na compreensão geral de uma distribuição ordenada.

Essa postura enciclopedista e o direcionamento metodológico a partir de um método comparativo teriam sido ratificados, ainda, por seus estudos em Freiberg. Depois de passar pela Academia de Comércio de Büsc, Humboldt freqüentou em Freiberg os cursos de geologia, mineralogia, topografia, tecnologia mineira, física, direito e matemática, dedicando-se por conta própria à paleontologia e à química (GAYET,1995). O trabalho nas minas que se sucede, quando enfim é nomeado assessor do Departamento de Berlim, ainda no ano de 1792, teria servido de fonte para seus esforços comparativos. Humboldt, não conseguindo restringir-se aos trabalhos burocráticos, chamava para si as pesquisas; descia até as minas; trabalhava ativamente na área, revelando assim as inquietações da juventude e a predisposição para o trabalho de campo, para a análise empírica (RUPKE, 2008). Isso lhe permitiu realizar pesquisas mineralógicas que, breve, lhe suscitariam os anseios de estender suas inquietações científicas às regiões mais longínquas do planeta, às terras exóticas que aprendera a amar já em suas primeiras lições escolares (RUPKE, 2008). Nestas pesquisas já se percebe em Humboldt a necessidade de comparar áreas distintas e inferir, a partir delas, correspondências e regularidades que resultassem em uma compreensão sistemática da diversidade natural.

Os propósitos de ampliação das fronteiras de pesquisa de campo seriam, nessa perspectiva enciclopedista e comparativa, passos indispensáveis no projeto maior de distribuição e organização sistemática da natureza. Ainda em defesa dessa via de análise podemos colocar a série de viagens exploratórias que Humboldt inicia a partir de 1796, quando herda 320.000 francos com a morte de sua mãe. Naquele tempo, tais viagens caracterizam-se pelo grande aparato tecnológico utilizado na aferição das áreas. Para além de uma busca informativa e curiosa, trata-se de expedições científicas, com trabalhos de campo sistematizados e transcritos sobre uma perspectiva metodológica rigorosa.

De posse dessas técnicas e tendo-as aplicado em suas viagens pela Europa e, com maior acuidade, na Espanha, Humboldt e Bonpland realizam a lendária viagem às Américas entre os anos de 1799 a 1804. Esta viagem, como é de conhecimento geral, marca uma nova concepção do continente e estrutura uma forma de construção sobre as informações geográficas ( GAYET, 1995; RUPKE, 2008) como nunca antes composta. Humboldt realiza uma série de catalogações de novas espécies de plantas e animais; traça com precisão novas cartas topográficas; estuda a diversidade vegetal e estabelece relações entre essa variação e a latitude; faz estudos meteorológicos; traça perfis topográficos; analisa a perspectiva histórica de formação do relevo; faz estudos sobre o magnetismo (PÉREZ, 2002); e, com seus instrumentos, reúne um conjunto vasto de aferições que serão posteriormente alvo de análise.

A partir destes trabalhos, fortemente marcados por informações sistematizadas, a obra de Alexander Von Humboldt, começará a gerar uma nova perspectiva metodológica que comporá, a partir de então, todos os seus trabalhos e que influenciará a formação da Geografia e das demais Ciências da Terra: Humboldt institui o valor das medidas e das atribuições numéricas como metodologia aplicada à compreensão da natureza, alinhando-se assim aos pressupostos gerais do racionalismo de cunho newtoniano na ciência. Pois passa a considerar que os números refletem matematicamente uma ordenação disposta à natureza. É a partir dessa concepção que se torna possível uma série de sistematizações, operadas no Essai sur la géographie des plantes, Le voyage aux régions equinoxiales du Nouveau Continent, Ansichten der Natur e mesmo no Kosmos. Em alguns casos ele trabalha com a aferição de espécies de plantas, se valendo das já reconhecidas e catalogadas por seus contemporâneos e por ele mesmo; para inferir a quantidade e as possibilidades das não- catalogadas, ele precisa se valer da análise geográfico-matemática da distribuição da vegetação e, desse modo, ponderar as espécies e famílias mais recorrentes em determinados climas e formações geológicas. Outra expressão do seu método quantitativo é a criação das célebres isolinhas, que representam numa escala cartográfica (geometricamente) as variações e conformidades dos diferentes aspectos e elementos naturais, tais como temperatura, altitude, latitude. 
Além do que já foi mencionado, devemos destacar ainda sua estreita relação com os cientistas do período. Entre eles, Laplace (1749-1827), formulador de uma concepção mecânica do Sistema-Mundo. Em verdade, Humboldt comungará de algumas das idéias de Laplace e inclusive o citará no Cosmos acerca da previsibilidade e da possibilidade de antever com exatidão, no caso das marés, o tempo e o lugar em que ocorrerão (HUMBOLDT, 1874a, 287-288). Essa concepção de Laplace representa, no período, um mecanicismo estrito, levado a cabo com a supressão de toda e qualquer medida de liberdade, uma completa e inelutável conseqüência causal posta em marcha. Para Laplace (In: Havermann,1967):

... tudo aquilo que virá a ocorrer no futuro estaria predeterminado, completamente e sem a menor exceção, pelo o que ocorreu no passado. Nada pode ocorrer senão aquilo que necessariamente tem que ocorrer, e tudo aquilo que necessariamente tem que ocorrer, ocorrerá. (HAVEMANN, R., 1967 p.94)

Caso, Humboldt limitasse a apenas este simples métodos não poderíamos reconhecer em seus trabalhos muito mais do que a conformação de um vasto campo de informações empíricas ordenadas sob os pressupostos correntes de um mecanicismo estrito. A natureza seria, nessa leitura, o conjunto dos fenômenos, a apresentação restrita de um domínio que deve falar a linguagem imposta pela razão, pela força da construção lógica. Procurar leis; conectar particulares numa linha geral de explicação; reduzir a leis mediante indução; representar graficamente a disposição matemática dos fenômenos: nada parece divergir do propósito geral de uma racionalidade posta. Entretanto, outros aspectos diametralmente opostos estão ligados ao pensamento de Humboldt e que, em verdade, fazem de seu labor científico a empresa original que nos esforçamos aqui por explicar.

\section{TELEOLOGIA, ORGANICISMO E FISIONOMIA EM HUMBOLDT: o fundamento de uma ordenação natural (superfície da Terra)}

Embora tenhamos visto que muitos dos pressupostos da ciência humboldtiana dialoguem com uma perspectiva mecanicista, temos que a consideração dessa perspectiva está introduzida ou absorvida em uma explicação geral mais ampla para o conjunto da natureza. Mesmo nos primeiros trabalhos de Humboldt podemos notar uma série de pressupostos metodológicos e conclusões que caminham na direção contrária das diretrizes mecanicistas.

Chama à atenção de Humboldt, ainda nos anos que segue em sua função como assessor do Departamento de Minas de Berlim, a relação existente entre o desenvolvimento das plantas e a luminosidade ambiente, graças às suas observações e análises nas áreas pouco iluminadas das minas. A contribuição antiga de Willdenow que influenciara seus primeiros trabalhos reaparecerá nessa primeira preocupação de relacionar os fatores externos com a perspectiva de desenvolvimento das plantas. Essa iniciativa será fundamental nos seus trabalhos futuros, sobretudo nas pesquisas realizadas no continente americano e na compreensão de uma interconexão entre os elementos da natureza. Antes disso, contudo, suas investigações fitogeográficas o conduzem à discussão elétrica em voga na ciência de final do século XVIII. Gayet (1995) considera que o direcionamento da pesquisa fitogeográfica para as polêmicas da eletricidade se dará porque Humboldt percebe a relação entre o crescimento das plantas e o estímulo fornecido por corpos externos. O que se deve destacar, entretanto, é a noção de que existe neste processo um agente que, a esse tempo, se correlacionaria com a eletricidade ou sua geração. Nesta concepção os seres vivos seriam dotados de uma uma força interna, que em atuariam em conjunto em todos os seres, ao mesmo tempo em que ligariam os seres a natureza em uma totalidade orgânica e organizada, acarretando assim o desenvolvimento da natureza e a evolução de seus seres.

Coloca-se com essa discussão sobre a eletricidade a polêmica envolvendo a visão geral de natureza; mais especificamente, a discussão acerca dos princípios pelos quais o saber deve se orientar na análise e compreensão do mundo natural. O que se põe em xeque com os experimentos elétricos

Mercator - volume 9, número 20, 2010: set./dez. 
no final do século XVIII, cujo representante maior foi Galvani (dos quais Humboldt também fez parte), é justamente a adoção do mecanicismo como fundamento último para a sistematização da natureza. A recusa à concepção de uma natureza estritamente mecânica reduzida às leis de causa e efeito é matéria das mais controversas neste contexto, e Humboldt, mesmo incorporando muitos dos elementos do mecanicismo em seus trabalhos, é um dos que caminham na direção oposta na compreensão geral da natureza. Nestas pesquisas de final do século XVIII o que está em jogo é a (re)colocação do argumento teleológico na explicação dos fenômenos naturais. Duas correntes de pensamento se abrem em torno da discussão elétrica: uma vai considerar as reações dos seres vivos e suas descargas elétricas como resultado do estímulo provocado pela condução da eletricidade através das placas metálicas usadas nos experimentos (adeptos da excitabilidade); e outra vai reconhecer nos seres uma força intrínseca, que se reverte em descargas elétricas mensuráveis (adeptos do vitalismo) (GAYET, 1995).

Humboldt realiza diversas pesquisas nessa área e logo se alia aos vitalistas. Sobre o tema, publica seus Versuche über die gereizte Muskel- und Nervenfaser em 1795. Além desse trabalho, o artigo Die Lebenskraft, oder der rhodische Genius também de 1795, publicado em As Horas, jornal editorado por Schiller, trata, numa perspectiva alegórica, justamente da defesa dessa concepção. Não obstante, a concepção vitalista carregava os resquícios de uma explicação teo-teleológica, quer dizer, trazia para dentro das ciências o elemento misterioso, descendo o véu do obscurantismo sobre os fenômenos naturais. Havia à idéia de os corpos eram constituídos de múltiplas forças. Humboldt recusará a perspectiva vitalista pouco depois, em 1797, justamente por essa idéia de múltiplas forças dispersas:

... a reflexão, e os estudos constantes no domínio da fisiologia e da química, modificaram profundamente a minha crença, acerca das forças vitais distintas. No ano de 1797 declarei, no fim do meu ensaio acerca da irritabilidade nervosa e muscular, que por nenhum modo aceitava a preexistência de tais forças. (Humboldt, 1953, p. 202).

Na segunda edição dos Ansichten der Natur de 1826, Humboldt reapresenta o artigo sobre Die Lebenskraft, oder der rhodische Genius publicado em As Horas. Há, de fato, uma (re)significação dessa força vital, vista não mais como múltipla e dispersa no seio da natureza, mas como o fundamento último da unidade do mundo. Como veremos, a aproximação com Schelling e com o Romatismo alemão como um todo é que podem explicar essa nova publicação do artigo nos Ansichten. Afinal, a força vital é nada mais do que o élan entre todas as coisas existentes, a atividade que enche de vida não só os seres, mas também a esfera inorgânica. Orgânico e inorgânico representam, desse modo, a oposição cuja síntese é a sua própria idealidade, ou seja, cada parte, seja ela orgânica ou inorgânica, encontra na atividade o elemento transcendente da vida que conduz a natureza ao reino dos fins.

A idéia principal de Humboldt, portanto, está na perspectiva de unidade. Em carta à M.A. Pictet de 24 de janeiro de 1796, Humboldt já expressa a idéia de uma física do mundo capaz de compreender a natureza em plena relação, uma unidade indissociável das partes: "Eu concebo a idéia de uma física do mundo, mas sinto cada vez mais necessidade e vejo que pouco dos alicerces foram colocados para um tão vasto edifício" "I conceived the idea of a physical world, but I increasingly need and see that few of the foundations were put to a such wide building " (Humboldt apud Gayet, 1995, p. 23, trad. nossa).

Capel (1981) indicará na correspondência de Humboldt com Schiller uma data ainda mais remota para esta perspectiva de 'harmonia'. Em 1794, depois de ter chamado a atenção de Goethe com a publicação de Florae Fribergensis Specimen (1793), trabalho oriundo das suas investigações nas áreas de mineração, e ter tido com este acerca do papel da idealidade na produção das formas, Humboldt, na sua correspondência com Schiller, destaca a perspectiva de uma unidade nos processos naturais, um desdobramento histórico que se revela nas diferentes gradações vegetais e nas 
formas assumidas pela superfície da Terra (Capel, 1981: página?). É neste momento que, podemos afirmar que se define o caminho de Humboldt, pois é nessa idéia de uma física do mundo - ou geografia física, como a chamará mais tarde - que ele depositará todos seus esforços; é este, enfim, o ponto para o qual conflui o conjunto de suas investigações e pensamentos. Tudo o que se abre aos olhos de Humboldt se associa a partir de então com a perspectiva de uma ligação fundamental do Universo - principalmente depois de sua estada em Jena no ano de 1797, quando passa grande parte de seu tempo com Goethe. Os sonhos de percorrer o mundo não são mais uma vã ansiedade, mas os passos necessários para a compreensão do universo cósmico

Ainda em oposição ao mecanicismo nas ciências, Humboldt trabalha com Gay-Lussac (aliado às pesquisas de Berthollet), em 1805, na reformulação de antigas concepções acerca da composição molecular da água, a partir da reação entre quantidades aferidas de oxigênio e hidrogênio. Essa discussão sobre a composição molecular está relacionada, naquela ocasião com as reformulações das diretrizes gerais do mecanicismo na explicação dos fenômenos químicos, já que não havia aqui uma justaposição ou soma de elementos, mas uma reação ou composição que aparecia como síntese. Humboldt confessa em nota sobre sua viagem com Gay-Lussac que ignorava o alcance teórico dessa pesquisa em conjunto com o francês: "Eu também colaborei com esta parte dos experimentos, mas só ele (Gay-Lussac) compreendeu a importância do resultado para a teoria" "I also work with this part of the experiments, but he (Gay-Lussac) understood the importance of the result to the theory". (Humboldt, s.d., p. 234, trad. e parênteses nosso). Não obstante, a concepção de uma relação indissociável entre os elementos da natureza e a consideração da perspectiva teleológica, eram pontos já incorporados ao pensamento de Humboldt - sobretudo pelos contatos com Goethe e suas obras antes da viagem ao continente americano, bem como pela relação estreita com os cientistas do período. As novas formulações dos estudos magnéticos na física, as discussões sobre a matéria na química e a perspectiva teleológica no estudo dos seres vivos já se apresentavam como um contraponto à perspectiva estritamente mecânica da natureza.

É ainda no ano de 1805 que prepara a publicação de sua Essai sur la géographie des plantes, obra que ele considera a mais importante das que está produzindo no período, como revela em carta enviada a M. A. Pictet em 3 de fevereiro de 1805 (Humboldt, s.d., p. 127). Nesta obra, a diversidade vegetal está intimamente associada às variações de relevo e clima em um processo de construção e redefinição contínua pelas disposições gerais da região. Como Humboldt (1990 [data original?]) mesmo sugerirá, a géographie des plantes "É a ciência que considera os vegetais sob os resultados de sua associação local nos diferentes climas." "is the science that considers the plants on the results of its local association in different climates." (HUMBOLDT, 1990, p. 14, trad. nossa). Esta géographie completa os trabalhos de classificação botânica e, segundo Humboldt (1990), é "uma parte essencial da física geral" "an essential part of general physical" (p. 13, trad. nossa).

O princípio da unidade está aqui esclarecido, e, é sob ele que se apresenta a composição, a distribuição e a variação numérica das plantas. $\mathrm{O}$ apelo aos números e a perspectiva quantitativa do conhecimento estão inseridas na idéia maior de uma unidade da diversidade natural.

Essa noção de unidade, sobretudo, baliza a sistematização das informações e representações levadas a cabo na sua expedição à América. Humboldt define o sentido geral de sua pesquisa no Prefácio de Le voyage aux régions equinoxiales du Nouveau Continen:

Eu tinha em vista um duplo objetivo nas viagens das quais eu publico agora a narrativa histórica. Desejava dar a conhecer os países que eu tinha visitado, e em recolher os fatos, tal como são montados, para elucidar uma ciência de que nós ainda possuímos praticamente o esboço, e que tem sido vagamente denominada de História Natural do Mundo, Teoria da Terra, ou de Geografia Física. O último destes dois objetos pareceu-me o mais importante. Eu estava apaixonadamente dedicado à botânica e certas partes da zoologia, e estava lisonjeado de mim mesmo porque nossas investigações poderiam acrescentar algumas novas espécies às já conhecidas, tanto nos reinos animal e vegetal; mas, priorizando a conexão dos fatos largamente observados ao conhecimento de fatos isolados, embora novos, a descoberta de um

Mercator - volume 9, número 20, 2010: set./dez. 
gênero desconhecido pareceu-me muito menos interessante do que uma observação sobre as relações geográficas da vegetação do mundo, sobre as migrações sociais das plantas, e do limite da altura que as diferentes tribos atingiram sobre os flancos das Cordilheiras. (HUMBOLDT, 1907, introdução, trad. Nossa)

Le voyage aux régions equinoxiales du Nouveau Continen, obra que concatena as contribuições de sua expedição com Bonpland à América, dispõe uma série de informações e representações e é trabalhada e publicada de 1807 até 1827 (Giner \& Funetes In: Humboldt, 1874a.). Tratou-se aqui de um grande levantamento que servirá de base para suas análises futuras, inclusive como objeto de comparação com outras áreas no projeto maior de encontrar a unidade dinâmica das variações regionais. A discussão acerca da unidade é traduzida nessa obra sob uma perspectiva fisionômica, quer dizer, trata-se de uma descrição e enumeração das coisas que são dadas a conhecer na área de pesquisa e, a partir deste conjunto de informações empírico-matemáticas, abrem-se as formulações em torno de princípios gerais e a apresentação de uma ligação fundamental entre tudo o que foi exaustivamente descrito. Esse caminho metodológico também é, como destacamos, empregado no seu Essai sur la géographie des plantes.

O que fica patente é que as contribuições e as informações adquiridas pelas metodologias afeitas ao mecanicismo se inserem na perspectiva maior de pensar a diversidade natural em sua unidade dinâmica. Não se trata de uma lei como pura abstração, mas de uma lei que deve expressar a relação indissociável entre a parte e o todo e, desse modo, refletir os pressupostos gerais de uma compreensão da realidade não-linear, considerada sob a concepção teleológica da natureza. A concepção de uma natureza atuando segundo fins se apresenta no arranjo sistemático do seu trabalho e em inúmeras de suas passagens. Nos Ansichten der Natur, por exemplo, nos diz:

Tudo anuncia um mundo de forças orgânicas em movimento. Em cada matagal, na casca gretada das árvores e na terra que cavam os himenópteros, a vida agita-se e faz-se ouvir, como uma das mil vozes que a natureza envia à alma piedosa e sensível do homem. (p. 270)

Considerando nesse momento somente a perspectiva fisionômica de unidade da realidade, podemos ver que é ela quem justifica o agrupamento dos particulares na direção do geral, já que cada parte está em franca comunicação com a totalidade e permanece em sua composição como elemento dinâmico na definição das características que se dão a ver. A variação regional sob princípios gerais, tão cara ao saber geográfico moderno, está assentada nessa perspectiva de unidade orgânica da realidade, em que os elementos específicos dialogam e se comunicam com as operações dinâmicas gerais da realidade, produzindo novas formas e revelando objetivamente uma diversidade regulada.

Além das vantagens que lhe são próprias, cada zona tem também o seu caráter determinado. Deixando certa liberdade ao desenvolvimento anômalo das partes, o organismo, em virtude de um poder primordial, submete todos os seres animados e todas as plantas a tipos bem definidos que se reproduzem eternamente. (p. 283)

Entretanto, em Humboldt essa perspectiva teleológica está para além dos aspectos objetivos das formas naturais; ela subentende uma relação ainda mais completa, na qual pretende conformar os recursos metodológicos mecanicistas e a concepção teleológica fisionômica com o movimento romântico alemão de início do século XIX. Esta ligação se apresenta sob o conceito de paisagem, que busca não só essa união, mas igualmente um novo saber capaz de confluir todos os ramos do conhecimento, todos os campos metodológicos que o compõem e, na mesma medida, oferecer uma resposta científica para o impasse ontológico entre as cosmovisões materialista e idealista. 


\section{A PAISAGEM E UNIDADE: O PAPEL DO PENSAMENTO ROMÂNTICO ALEMÃO}

Pudemos ver que Humboldt realiza uma incorporação das metodologias do campo do saber mecanicista e das perspectivas teleológica e organicista da natureza. Aparentemente contraditórias, na verdade excludentes, essas vias não podem sem qualquer dificuldade serem aproximadas, na medida em que partem de noções cosmológicas distintas e compreendem um conjunto diversificado de diretrizes e pressupostos conceituais. Entretanto, a tarefa de aproximar esses dois caminhos não é de todo original: ela já se apresenta, por exemplo, na explicação física de Leibniz, que pretende aproximar e confluir em um único sistema geral as causas eficientes e finais - em outras palavras, os princípios mecânicos com os teleológicos. Outro que apresenta essa aproximação é Kant, considerado na perspectiva total de seu projeto Crítico. Com seus estudos geográficos e sua análise sobre as raças, Kant introduz no conjunto de ordenações mecânicas anunciadas na Crítica da Razão Pura (1781) e nos Primeiros Princípios Metafísicos da Ciência da Natureza (1786) a concepção teleológica que permite conceber na natureza um fim independente da razão (sujeito transcendental), uma relação todo-partes e uma comunicabilidade entre causa e efeito que distam, em grande medida, das determinações causais mecânicas sem, contudo, renunciar a elas. A concepção de uma natureza teleológica será apresentada com sua Crítica da Faculdade de Julgar (1790), estruturando pelo caminho dos juízos reflexivos um novo arranjo sistemático capaz de compreender o mundo natural atuando segundo a fins (Marques, 1987), sem abandonar a perspectiva mecanicista atribuída aos outros juízos, os determinantes. Em verdade, essa formulação geral do projeto Crítico kantiano é já uma recuperação das idéias de Leibniz na Crítica da Faculdade de Julgar, apesar de toda renuncia do saber monádico constitutivo (renuncia de tratar da coisa em si) e de ter caminhado anos antes na defesa das idéias gerais mecânicas.

Relacionar Humboldt diretamente com essas idéias de Kant no que diz respeito à concepção de unidade dos fenômenos e na construção de uma visão geral que pretendia, no campo de análise geográfica, uma solução para o embate mecanicista e teleológico é matéria controversa, com a qual há lidado de maneira extremamente relevante Hartshorne (1958). Acerca da possibilidade de uma influência direta da Geografia kantiana e sua concepção cosmológica na produção de uma ciência humboldtiana, Hartshorne defende que:

Por lo tanto, concluimos que 1) años más tarde, Humboldt estudió el postulado de Kant tal como se publico en 1802, e hizo un importante uso de él; 2) cuando escribió su propia formulación básica, en 1793, es casi seguro que no tenia ante si ninguna de las numerosas copias manuscritas de las clases de Kant que estaban circulando en Alemania; y 3 ) es enteramente posible que hubiera visto alguna de esas copias en una fecha algo anterior, o que hubiera oido hablar del concepto de Kant a través de cualquiera de las muchas fuentes posibles, pero no tenemos una muestra evidente de ello. Es enteramente posible, si no probable, que los dos hombres llegaran a conclusiones similares de manera completamente independiente. (p. 41-42)

Para Nicolson (In: CUNNINGHAM \& JARDINE, 1990), entretanto, existe uma ligação direta entre as formulações geográficas de Kant e o projeto sistemático para compreensão da natureza que Humboldt apresenta já em 1793, rompendo com a mera descrição da natureza fornecida pelo sistema de Lineau (Linnaean System). Embora Humboldt pareça realmente ter assumido uma leitura diferente da meramente descritiva com sua Florae Fribergensis Specimen, sua concepção teleológica da natureza esta assentada no princípio de unidade que se edifica em seu pensamento algum tempo depois. Na verdade, pode-se dizer, com alguma segurança, que a concepção de uma natureza teleológica em Humboldt tenha comunicação com as idéias de Kant, mesmo que indiretamente, pelo papel desempenhado pelo contato com Goethe em 1793 e, em geral, com o Sturm und Drang.

Como vimos, ainda em 1793 Humboldt tem com Goethe acerca de sua publicação Florae Fribergensis Specimen e se atenta, desde então, para uma série de ligações que se sucedem entre a disposição geral da natureza e um princípio de finalidade. Além da carta de Humboldt a Schiller de

Mercator - volume 9, número 20, 2010: set./dez. 
que nos fala Capel (1981), o próprio Humboldt expressa de maneira clara o que há representado para seu pensamento as idéias introduzidas pelo movimento pré-romântico e, em especial por Goethe, no tempo que passa em Jena no ano de 1796. Humboldt confessa no seu epistolário de 1806 que essa idéia de unidade é o fundamento das suas sistematizações e representações:

... apesar dos mil fenômenos e imagens que ocupam meus sentidos, o novo se tornava em seguida familiar e o que parecia exteriormente desconhecido se adaptava facilmente às antigas imagens; reconhecia nos bosques do Amazonas, e sobre os contrafortes dos Andes, que o mesmo sopro anima a mesma vida de um pólo a outro nas pedras, nas plantas, nos animais e no dilatado peito do homem. $\mathrm{O}$ sentimento da grande influência de Jena me persegue por todas as partes, já que as idéias de Goethe a respeito da natureza me transmitiram e, por assim dizer, me dotaram de novos órgãos. (HUMBOLDT, s.d., p. 143, trad. nossa.)

A apresentação de uma ligação entre os particulares com uma conexão geral, uma ligação estrutural entre os elementos que compõem a natureza será fundamental para a solução da dualidade mecânica e teleológica, mas, mais do que isso, essa concepção de unidade está associada com as diretrizes do que será o movimento romântico alemão, quer dizer, além da consideração de uma unidade e finalidade, os pressupostos da relação entre o homem e a natureza serão totalmente diferentes daqueles impostos pelas vias estritamente racionalistas e seus arranjos metodológico-analítico-formais. Aqui, para além de uma perspectiva fisionômica que reconhece as diferenças e particularidades materiais na construção de visão geral e ordenada, introduz-se o elemento humano, o sujeito a quem estas características particulares se dão a ver. Sob o conceito de paisagem, se expressa no saber científico de Humboldt uma construção que considera não só a dimensão fisionômica, mas também a estética da natureza.

Vimos já que Humboldt incorpora em seus trabalhos um conjunto de informações e dados, se valendo inclusive de metodologias quantitativas e afeitas ao saber mecanicista; igualmente, vimos que esse corpo de informações se associa com uma medida fisionômica da natureza orgânica que permitirá a ele estabelecer relações, explicar a conexão existente entre os elementos do mundo. A paisagem, sua descrição, funciona nessa perspectiva enquanto um registro, uma marca das diferentes regiões a serem consideradas na tentativa final de entender a atividade cósmica. Para Besse (2006), a perspectiva da paisagem que surge nesse contexto é a expressão de uma "fisionomia do espaço terrestre", a colocação de um dado, uma impressão a ser lida no campo da experiência; é ela quem permanecerá no final do século XIX e XX como campo ordenador do saber geográfico, abrindo em Vidal de La Blache (1845-1918) e Ratzel (1844-1904) uma relação do homem com esse emoldurar das características objetivas, a construção material de uma "inscrição" humana no corpo material da natureza. Entretanto, notamos que o fundamento geral que ordena seu saber, o princípio de unidade, dialoga não só com o campo estritamente formal do saber e seus pressupostos racionalistas, mas que está diretamente ligado com o pensamento de Goethe, em geral, com o movimento romântico alemão de início do século XIX. A paisagem, em verdade, é mais do que um registro, uma marca do mundo a ser reconhecida e integrada numa visão geral teleológica; ela representa, na mesma medida, o captar do sujeito que coloca no processo de apreensão da natureza sua imaginação, o papel ativo do olhar na construção da coisa vista.

A paisagem nessa perspectiva estética em Humboldt está em consonância com a significação da natureza colocada por Goethe como processo de formação-transformação, como o próprio Humboldt confessa no epistolário que destacamos: "as idéias de Goethe a respeito da natureza me transmitiram e, por assim dizer, me dotaram de novos órgãos." the ideas of Goethe on the nature sent me and equipped me the new organs (HUMBOLDT, s.d., p. 143, trad. nossa). Origem de nova forma, cada figura representa um processo, uma dinâmica própria de uma relação entre o invisível e o empírico. Enquanto se pronuncia o protofenômeno , a apetição pela qual se orientam todas as 
formas, enquanto se apresenta um modelo ideal, o protótipo, arquétipo perfeito que aspira todo ser, se constrói objetivamente uma imagem que é o retrato de toda essa confluência, a representação de uma unidade que não pode ser alcançada por nenhuma de nossas representações.

Delimitada em si, cada parte carrega o que haverá de ser, cumpre a plena realização pela relação sempre aberta com o invariável e a totalidade. Por sua condição, a parte é fundamento do novo; de sua ligação com as outras partes e com o infinito surge a mudança, a dinâmica que enreda novamente essa peça, que mantém a comunhão entre tudo o que existe objetiva e subjetivamente. A paisagem representa a forma, melhor dizendo, o conjunto das formas (morfologia) e, desse modo, exprime por sua imagem a construção que se opera na cena contemplada. As formações, sobretudo as vegetais, revelam nessa perspectiva da paisagem a ligação universal entre cada particular e o todo que se abre em plena relação.

A paisagem, numa dupla introdução sensível que escapa às cadeias discursivas do entendimento, organiza num instante o reencontro patético da totalidade. Ela é a coincidência do universal e do particular, onde, sob o modo do afeto, se realiza o poder do conhecimento absoluto. A paisagem particular que se abre ao olhar deixa ver simultaneamente o todo: apreensão brusca da plenitude através do efêmero. Ela é símbolo, em íntima ressonância com o golpe de vista diante do qual ela se revela: "o verdadeiro símbolo é aquele em que o particular representa o universal, não como ilusão ou imagem, mas como revelação viva e instantânea do inexplorável.” (BESSE, 2006, p. 58)

Pensando ainda numa correspondência com as idéias de Goethe podemos observar que a paisagem humboldtiana se atrela à possibilidade de uma apresentação do infinito no finito. Nas palavras de Goethe: "Se queres caminhar para o infinito/ Anda para todos os lados no finito" In the words of Goethe: "If you want go to the infinite / Walk for all sides in the finite (GOETHE apud MOLDER In: GOETHE, 1997, p.16). Na verdade, essa perspectiva goethiana tem paralelo com duas construções em Humboldt. Em um primeiro momento, na perspectiva do método comparativo. Ao contrário do que nos fala Capel (1981), o fundamento do método comparativo humboldtiano, que guiará seu afã por integrar em uma explicação geral diferentes regiões e suas particularidades, parece caminhar da influência exercida por Gotinga para as idéias gerais de natureza de Goethe, ou seja, parece diretamente relacionado com essa busca do tipo, do arquétipo, do infinito na dimensão do finito: "Deixando certa liberdade ao desenvolvimento anômalo das partes, o organismo, em virtude de um poder primordial, submete todos os seres animados e todas as plantas a tipos bem definidos que se reproduzem eternamente." (HUMBOLDT, p. 283). A comparação entre diferentes formas, em diferentes lugares e condições, a perspectiva de uma geografia regional, é a opção metodológica de quem busca encontrar uma unidade, um tipo definido (arquétipo) naquilo que se apresenta de forma variável. Aí residiria também todo o sentido de um aparente esforço enciclopedista, afinal, quanto mais estendermos nossas possibilidades de observação e comparação, mais perto chegaremos do modelo ideal (infinito) que jaz em toda particularidade (finito) e que as liga numa única e mesma representação. Em um segundo momento, a medida de uma ligação entre finito e infinito é a marca do valor central do conceito de paisagem na proposta de compreensão da natureza. A paisagem apresenta a cena, dispõe o que importa então para Humboldt, a tomada no instante de uma totalidade pela medida do particular. Ao tempo que coloca as características de uma determinada região, a paisagem recobra a extensão que não pode ser captada, ela evoca a continuidade; ela, ao tempo que exprime a comunhão universal na forma, lança a perspectiva do que ali não se apresenta, nas palavras de Besse (2006): "Todos os pontos do espaço, as margens, os centros, o longe e o perto marcam essa insistência do infinito no finito, que trabalha no interior da paisagem e a define." (p. 07).

A paisagem em Humboldt, nessa perspectiva estética, apresenta uma aproximação entre razão e sensibilidade, que também estão em consonância com as idéias de Goethe, mas sobretudo com as de Schiller e Schelling (1775-1854). Em Schelling (2001a; 2001b), especificamente, “a natureza é

Mercator - volume 9, número 20, 2010: set./dez. 
o espírito exteriorizado, disperso em todas as formas naturais, enquanto que o espírito é a natureza profunda e interiorizada." "nature is the spirit exteriorized, scattered in all natural forms, while the spirit is deep and internalized nature." (MARÌ, 1989, p. 170, trad. nossa). A figura do gênio, o artista capaz de tornar prática a manifestação abstrata da intuição intelectual, assume um papel crucial; ser capaz de, por intuição estética, traduzir objetivamente o que se apreende na intuição, é o gênio elemento chave da filosofia schellingiana; é, assim, tanto um produto da natureza (por sua inconsciência) como um produto da liberdade, já que ordena conscientemente os processos e a mensagem na construção da obra de arte. A filosofia da arte realiza a síntese final na imagem do gênio porque reaproxima este a natureza e o espírito numa condição privilegiada que revela o progresso e o sentido último de uma realidade em busca do Absoluto. Humboldt (1874), citando Schelling, demonstra o que essa concepção empreende na sua visão de natureza:

A natureza, disse Schelling em seu poético discurso sobre as artes, não é uma massa inerte; é para aquele que sabe penetrar-se de sua sublime grandeza, a força criadora do Universo agitando-se sem cessar, primitiva, eterna, que engendra em seu próprio seio, tudo o que existe, perece e renasce sucessivamente (p. 37, trad. nossa).

É, em poucas palavras, a concepção de uma natureza desdobrando-se sobre si mesma numa perspectiva reflexiva e desenvolvendo um par dialético com a atividade do espírito, nas palavras de Humboldt (1874), "segundo uma evolução em espiral" (p. 45, trad. nossa) " in accordance with the views of a spiral evolution" (1858, p. 61). Essa natureza em transformação remete a uma síntese integradora na intuição. A paisagem, sua representação pela pintura ou pela descrição proso-poética em Humboldt servirá justamente a este propósito. Gayet (1995), utilizando as palavras de Humboldt no II tomo do Cosmos, destaca o significado da representação artística da paisagem: "A pintura da paisagem, para Humboldt, não é puramente imitativa. Ela deve ser 'o fruto de uma contemplação profunda da natureza e da transformação que se opera no interior do pensamento."” "The painting of the landscape, to Humboldt, is not purely imitative. It should be 'the result of a profound contemplation of nature and the transformation that operates within the mind." (p. 182, trad. nossa). Ou seja, a medida artística coloca o homem, sua imaginação, à atividade do espírito, no processo de construção da paisagem.

Enquato relação indissociável entre sujeito e objeto, a paisagem representa não só a medida de uma totalidade entre os elementos da natureza, mas, igualmente, uma unidade entre a construção do pensamento e o processo de formação-transformação (metamorfose) da natureza.

Tudo quanto dá caráter individual à paisagem: o contorno das montanhas que limitam o horizonte num longínquo indeciso, a escuridão dos bosques de pinheiros, a corrente que se escapa de entre as selvas e bate com estrépito nas rochas suspensas, cada uma destas coisas tem existido, em todos os tempos, em misteriosas relações com a vida íntima do homem. (HUMBOLDT, 1952, p. 212)

A vista da paisagem, sua disposição pela medida do dom artístico, dá um passo adiante na formulação do saber, na medida em que aproxima razão e sensibilidade, a atividade do espírito e a construção da natureza. Como aponta Ricotta (2003), os limites na compreensão do mundo são as bases necessárias para o cenário da imaginação, aquilo que torna humana a interpretação da natureza. Segundo o próprio Humboldt no Tomo I do Cosmos (1874):

Todo cuanto nuestros sentidos percíben vagamente, todo cuanto los parajes románticos presentan de mas horrible, puede llegar á ser para el hombre manantial de goces; su imaginacion encuentra en todo medios de ejercer libremente un poder creador. En la vaguedad de las sensaciones, cambian las impresiones con los movimentos del alma, y, por una ilusion tan dulce como fácil creemos recibir del mundo exterior lo que nosotros mismos sim saberlo hemos depositado en él. (p. 05-06) 
É esta perspectiva de unidade trazida pelo conceito de paisagem que define o valor e o caráter da ciência humboldtiana, na medida em que ela é mais do que um simples reconhecimento e ordenação dos elementos empíricos; antes disso, ela é a confluência de todos estes pressupostos ordenadores e materiais sob o sentido geral de uma natureza e realidade concebida à maneira dos românticos. A paisagem é que permite essa aproximação e é ela que compreende e soluciona a tensão existente entre estes pressupostos contraditórios.

\section{A CIÊNCIA HUMBOLDTIANA: paisagem como solução do problema ontológico (geografia como resgate empírico)}

Vimos que há uma dupla perspectiva da paisagem em Humboldt: uma ligada a perspectiva objetiva, ao reconhecimento de uma fisionomia que dá feição própria às regiões e emoldura a superfície da Terra; e outra atrelada à dimensão estética, que reconhece uma aproximação entre sujeito e objeto e mesmo uma atividade criadora do espírito na produção da paisagem. O impasse colocado por estas duas perspectivas diz respeito à contradição que envolve a adoção delas em conjunto. Na perspectiva estética impera a dimensão subjetiva; a paisagem é a cena que encontra legitimidade no campo de visão do sujeito; é a manifestação da idealidade no processo de captação e construção do mundo. Na perspectiva fisionômica, por sua vez, a dimensão objetiva existe como impressão, como dado do mundo e, nesse âmbito, independe sua existência e formação da dimensão subjetiva do observador, percebida então como um desvio, uma capacidade que deve se adequar às disposições de um mundo dado em sua realidade. Segundo Besse (2006):

Tanto um subjetivista quanto um realista reconhecem que a paisagem é da ordem do visível. A verdadeira questão é a do estatuto atribuído ao visível, de sua função, e mesmo de sua significação. Grosso modo: é o espectador que define a paisagem? Neste caso, o visível é relativo a um ponto de vista, a um enquadramento, é uma imagem. Ou há o visível, a paisagem, havendo ou não um olhar? Neste caso, o visível e a paisagem são pensados como objetivos, como uma face exterior, um rosto, uma fisionomia, e então o problema do espectador eventual consiste em se ajustar perceptivamente e intelectualmente a esta fisionomia: a paisagem não é uma imagem, é uma forma. Na verdade, estas duas posições, ou hipóteses, constituem dois pólos extremos, entre os quais há uma tensão na experiência paisagística: uma tensão entre a atividade do espectador, de um lado, e, de outro, o fato de que há algo a ver, algo que se dá a ver. Uma posição subjetivista coloca o peso sobre o papel constituinte do olhar. O realista, por sua vez, coloca o peso sobre a idéia de que há algo além da representação, ele quer perceber no visível o traço de outra coisa que não é só o visível. (p. 64-65)

Aqui se apresenta uma tensão entre as cosmovisões materialista e idealista; uma tensão que acompanha o saber filosófico e que era o ponto alto da discussão filosófica de final do século XVIII e início do século XIX na Alemanha. Desde o projeto Crítico kantiano, a perspectiva de uma formulação sistemática capaz de resolver a tensão entre sujeito e natureza domina o pensamento filosófico.

É nesse ínterim que se edifica o idealismo alemão, partindo de Fichte, passando por Schelling e Hegel. Bunksé (1981), citando Halina Nelken, nos fala, "contra o idealismo absoluto de Hegel e Schelling, Humboldt instalou o conceito racional de harmonia e unidade da natureza..." "against the absolute idealism of Hegel and Schelling, Humboldt set the rational concept of harmony and unity in nature...". Ou seja, essa tensão ontológica não é ignorada por Humboldt, ele a vivencia, tem com estes autores acerca da concepção de natureza e, recuperando o valor do empírico, assimila uma série de pressupostos do pensamento filosófico alemão, em especial da Naturphilosophie.

A idéia de unidade é o ponto alto desse pensamento humboldtiano; é ela, incorporando o empírico e a imaginação, que permitirá não só a consideração dos elementos da natureza em plena relação, mas também a do papel criativo do homem na própria construção destes elementos e, sobretudo, na sua representação. Knight (UNNINGHAM \& JARDINE, 1990), destacando a correspondência ou proximidade do pensamento de Humboldt com a fase poética de Davy — famoso

Mercator - volume 9, número 20, 2010: set./dez. 
químico do século XIX influenciado pelo romantismo - , deixa ver esse propósito maior de abarcar a perspectiva estética e científica da realidade nas obras humboldtianas, em especial no Ansichten der Natur:

Humboldt procurou balancear a subjetividade e a objetividade; e seu (...) 'Quadros da Natureza' foi um esforço em pictóricas palavras de transpor o exótico cenário, informado pela botânica, geologia e zoologia. A ciência natural descritiva em Humboldt foi apaixonada, em consonância com o poema de Davy; e particularmente unindo a estética e a ciência. (p. 15, trad. nossa)

A paisagem, nesse sentido, é o conceito chave; ela compreende em harmonia o que se dá a ver e a imaginação que completa e ajuda a criar a cena contemplada. Essa confluência na perspectiva da paisagem é que caracteriza o que chamamos até aqui de ciência humboldtiana.

A natureza, estética e cientificamente operacionalizada, permitia por meio do conceito de paisagem realizar materialmente a metafísica da substância, convertendo o transcendental em objetividade. Assim, em Humboldt, a natureza se converteu em paisagem, que é particular e delimitada, fazendo parte de um todo, mas que na análise torna-se uma totalidade independente.

Agora é possível falar que a natureza como totalidade torna-se individualizada em paisagens, que funcionam e apresentam limites. Não haveria, na visão de Hunboldt, uma exclusão das perspectivas estéticas e fisionômicas da paisagem: elas eram complementares e permitiam um conhecimento ordenado e artístico simultaneamente. Bunksé (1981), utilizando citações de Humboldt, destaca:

Para Humboldt o conhecimento científico não tira o encantamento da natureza. "Eu não posso, portanto, concordar com Burke quando ele diz, 'é nossa ignorância acerca da natureza das coisas que causam toda nossa admiração, e principalmente excita nossas paixões"”. Humboldt pensava que esta posição levava a representar um falso preconceito, engendrando nas mentes incapazes de fazer conexões entre fenômenos individuais observados, erguendo a crença de "que o estudo das ciências exatas deve necessariamente esfriar os sentimentos, e diminuir o nobre encantamento subordinado à contemplação da natureza". De acordo com Humboldt, o contrário era verdadeiro: cada nova descoberta abria um novo labirinto; o estabelecimento de uma nova lei da natureza levava à descoberta de outras leis; instrumentos designados para provar a natureza "revelavam mais das suas infinitudes". Ciência não conduzia à "estéril curiosidade" mas, isto sim, à "profunda reflexão". (p. 138-139)

Para Dettelbach (1999), entretanto, é extremamente temerário falar em uma ciência humboldtiana, sobretudo quando assimilamos a ela as noções gerais da Naturphilosophie e sua concepção teleológica da natureza. Segundo ele:

As mais variadas facetas do trabalho de Humboldt podem, portanto, ser vistas como um projeto estético, um esforço reiterado para definir e representar uma sensibilidade ou 'olhar fisionômico'. Isto não é uma teoria holística, teleológica do cosmos, mas uma série de praticas culturais ligadas pela manifestação do poder e autoridade do filósofo. Neste sentido, não havia uma ciência humboldtiana, no sentido de uma ciência cósmica, determinística, uma teoria positiva do entendimento, das relações causais entre os fenômenos do cosmos, ou no sentido de um vitalismo cósmico que entendia todos os fenômenos do cosmos como o produto de uma força singular ou alma-do-mundo. (...)Humboldt não se preocupou em entender o mundo como uma grande cadeia de causa e efeito; ele estava distante como atualmente sabemos da impenetrável complexidade, densidade e historia do mundo físico para propor igualmente uma tal ciência. (502-203)

Dettelbach (1999) defende que na verdade o sentido do saber humboldtiano se associa com esse elemento integrador proposto pela associação de paisagem e mediação, enfim, como a introdução de uma "sensibilidade calibrada" na compreensão da natureza.

By juxtaposing landscape and precise instruments, the Tableau physique was defining a 'calibrated sensibility': it tied the cosmopolitan taste of the cultivated European to an account of sensation and 
measurement, and thereby naturalized and universalized it. The Tableau might serve as the icon of Humboldtian science, then, not because it proposed a theory of nature, or attempted what naturephilosophers tried discursively, but because it enacted or performed a sensibility, a human nature. (DETTELBACH, 1999, p. 503-504)

O que Detelbach assinala é relevante, mas deixa de lado a questão central dessa aproximação, que é justamente a solução de um impasse, de uma tensão que toma conta do saber no contexto de Humboldt. O que está em jogo é mais do que uma "sensibilidade calibrada"; antes disso, é a criação de uma forma de agir e pensar cientificamente que são de todo original. Humboldt coloca conscientemente sua contribuição no centro dessa tensão, confluindo diferentes legados na construção de uma ciência, a um tempo empírica e ordenadora e, a outro, sensível e imaginativa. $\mathrm{Na}$ sua grande obra, o Cosmos, que expressa verdadeiramente seu propósito e conflui suas idéias no que chamamos aqui de ciência humboldtiana, encontramos a manifestação do próprio Humboldt acerca do que está a produzir e da originalidade da ciência por ele criada.

La descripcion del mundo, considerado como objeto de los sentidos esteriores, necesita indubitablelmente del concurso de la física general, y de la historia natural descriptiva; pero la contemplacion de las cosas creadas, enlazadas entre si y formando un todo animado por fuerzas interiores, dá a la ciencia que nos ocupa en esta obra un carácter particular. (HUMBOLDT, 1874a, p. 42)

Essa ciência é mais do que se entende até então por ciência; ela é a confluência de múltiplos legados metodológicos; é a valorização do empírico e do transcendental, é a resposta, pelo conceito de paisagem, ao problema ontológico das aparentemente excludentes cosmovisões materialista e idealista. Sua ciência busca ordenações matemáticas para os fenômenos, a regularidade reconhecida na experiência pelo método de indução, assim como a compreensão de um telos natural, um conjunto de conexões reconhecidas na forma, o passo decisivo na introdução de uma sensibilidade romântica para além dos ditames restritos de uma ciência racionalista. Sintetizadora, essa ciência humbldtiana agrega não só diferentes legados, mas também, no reconhecimento espacial das variações, na apresentação regional de características próprias segundo princípios regulares, os elementos da natureza na sua relação harmônica com ela mesma e com o espírito, compreendidas nesse sentido sob o conceito de paisagem.

Para além dos limites reconhecidos, a ciência humboldtiana é uma ciência universal que procura apaziguar todos os caminhos dispostos ao humano em sua história intelectual. Científica, artística e filosófica, sua ciência representa o esforço de quem pretendeu com sua vida intelectual resolver com uma construção científica original o problema ontológico que acompanha a história do conhecimento.

\section{REFERÊNCIA BIBLIOGRÁFICA}

BENJAMIN, W. O conceito de crítica da arte no romantismo alemão. Trad. e notas Marcio Seligmann Silva. São Paulo: Iluminuras, 2002

BESSE, Jean-Marc. Ver a Terra: seis ensaios sobre a paisagem e a geografia. São Paulo: Perspectiva, 2006. BORHEIM In: GUINSBURG, J (org). O romantismo. São Paulo: Editora Perspectiva, 2005, p. 75-112.

BUNKSÉ, Edmunds V. Humboldt and an aesthetic tradition in geography. The Geographical Review, 71, 1981, no. 2

CAPEL, Horacio. Filosofía y ciencia en la geografía contemporánea: una introducción a la geografía. Barcelona: Barcanova, 1981.

CASTRILLÓN, Alberto. Fitogeografía, paisaje y territorialidad al comienzo del siglo XIX. Boletín Cultural y Bibliográfico. Número 46. Vol. XXXIV, 1997, editado - 1998.

CLAVAL, Paul. História da Geografia. Lisboa: Edições 70, 2006.

Mercator - volume 9, número 20, 2010: set./dez. 
CUNNINGHAM, A. \& JARDINE, N. Romanticism and the sciences. New York: Cambridge University Press, 1990.

DETTELBACH, The face of nature: precise measurement, mapping, and sensibility in the work of Alexander von Humboldt. Studies in history and philosophy of Biological and Biomedical Sciences. Great Britain: Elsevier Science Ltd., 1999, vol. 30, No. 4, pp 473-504.

DORNELAS, M. C. \& DORNELAS O. From leaf to flower: revisiting Goethe's concepts on the metamorphosis of plants. Braz. J. Plant Physiol, 17 (4), 2005, p. 335-343.

GAYET, Mirelle. Alexandre de Humboldt: le dernier savant universel. Préface Philippe Taquet. Presses universitairies de France, 1995.

GOETHE, J. W. A metamorfose das plantas. Trad., Introdução e Notas Maria Molder. Lisboa: Imprensa Nacional da Casa da Moeda, 1997.

GOETHE, J. W. Doutrina das cores. São Paulo: Nova Alexandria, 1993.

GOETHE \& SCHILLER. Companheiros de viagem: correspondências. São Paulo: Nova Alexandria, 1993.

GUINSBURG, J. (org.). O romantismo. São Paulo: Editora Perspectiva, 2005.

HARTSHORNE, Richard. Propósitos e natureza da geografia. São Paulo: Edusp, 1978.

HAVEMANN, Robert. Dialética sem dogma. Rio de Janeiro: Zahar Editores, 1967

HUMBOLDT, Alexander. Aspects of Nature, in Different Lands and Different Climates, with Scientific Elucidations. Translated by Mrs. [E.] Sabine, 1849.

HUMBOLDT, Alexander. Cosmos: A Sketch of the Physical Description of the Universe, Vol. 1

Harper \& Brothers edition, 1858.

HUMBOLDT, Alexander. Cosmos: ensayo de una descripcion física del mundo. Trad. Bernardo Giner \& Jose de Fuentes. Madrid: Gaspar e Roig Editores, 1874, Tomo I, II, III e IV

HUMBOLDT, Alexander. Equinotial regions of America. GEORGE BELL \& SONS. LONDON: PORTUGAL ST.LINCOLN'S INN. CAMBRIDGE, 1907. (v. 1,2,3)

HUMBOLDT, Alexander. Quadros da natureza. São Paulo: W. M. Jackson Inc., Vol. 1., 1952. (Clássicos Jackson)

HUMBOLDT, Alexander. uadros da Natureza. São Paulo: W. M. Jackson Inc., Vol. 2., 1953. (Clássicos Jackson)

HUMBOLDT, Alexander. Essai sur geographie des plantes. Paris: Éditions Européenes Erasmo, 1990. HUMBOLDT, Alexander. Cartas Americanas. Trad. Marta Traba. Venezuela: Biblioteca Aycaucho, s.d. KANT, Immanuel. Primeiros princípios metafísicos da ciência da natureza. Lisboa: Edições 70, 1990. KANT, Immanuel. Crítica da faculdade de julgar. Rio de Janeiro: Forense Universitária, 1995. KANT, Immanuel. Crítica da razão pura. São Paulo; Nova Cultural, 1999 (Os Pensadores)

KNIGHT, David M. Science in the Romantic Era. Aldershot, Brookfiled USA, Singapore, Sydney: Ashgate, Variorum, 1998.

KNIGHT, David In: CUNNINGHAM \& JARDINE. Romanticism and the sciences. New York: Cambridge University Press, 1990. (pp.13-24)

KOHLHEPP, Gerd. Scientific findings of Alexander Von Humboldt's expedition into the Spanish-American Tropics (1799-1804) from a geographical point of view. Anais da Academia Brasileira de Ciências, 2005, 77(2): 325-342.

LENIOR. In: CUNNINGHAM \& JARDINE. Romanticism and the sciences. New York: Cambridge University Press, 1990. (pp. 119-129)

LUKÁCS, Georg. Goethe y su época: precedido de Minna von Barhelm. Barcelona - México, D. F.: Ediciones Griyalbo, S. A., 1968b.

MARÍ, Antoni. Euforión: Espíritu y naturaleza de genio. Madrid: Tecnos, 1989.

MINGUET. In: HUMBOLDT. Cartas Americanas. Trad. Marta Traba. Venezuela: Biblioteca Aycaucho, s.d. MOLDER In: GOETHE. A metamorfose das plantas. Trad., Introdução e Notas Maria Molder, Lisboa, Imprensa Nacional da Casa da Moeda, 1997. 
NICOLSON In: CUNNINGHAM \& JARDINE. Romanticism and the sciences. New York: Cambridge University Press, 1990. (pp. 169-188)

PEREZ, Joaquím F. EI descobrimiento de la naturaleza: Humboldt. Três Cantos: Nívola, 2002.

REBOK, Sandra. La expedición de Alexander von Humboldt y su contribuición a la ciencia del siglo XIX. Lima: Instituto Francés de Estudios Andinos, Boletín del Instituto de Estudios Andinos, ano/vol. 32, no. 003, 2003.

RICOTTA, Lúcia. Natureza, Ciência e estética em Alexander von Humboldt. MAUD, 2003.

SHARPE, Lesley. The Cambridge Companion to Goethe. Cambridge University Press, 2002.

SCHELLING, F. Ideias para uma filosofia da natureza: prefácio, introdução e aditamento à introdução. Lisboa: Imprensa Nacional Casa da Moeda, 2001a.

SCHELLING, F. Filosofia da Arte. Introd. e notas Márcio Suzuki. São Paulo: Editora da Universidade de São Paulo, 2001b, p. 09-14.

Trabalho enviado em setembro de 2010 Trabalho aceito em dezembro de 2010 